\title{
Three-dimensional finite element modelling of excavation-induced tunnel wall movement and damage: a case study
}

\author{
HAOYU HAN*D, HONGYUAN LIU, ANDREW CHAN and THOMAS MCMANUS
}

School of Engineering, University of Tasmania, Hobart, TAS 7001, Australia
e-mail: haoyu.han@utas.edu.au; hong.liu@utas.edu.au; andrew.chan@utas.edu.au; thomas.mcmanus@live.com

MS received 3 December 2018; accepted 11 June 2019

\begin{abstract}
A three-dimensional elastoplastic finite element modelling is conducted for the back analysis of a tunnel collapse accident that happened at the Hobart Myer construction site, including the deformation and failure processes of an existing tunnel in close proximity to a basement excavation as well as further excavationinduced tunnel wall damage and collapse. The full three-dimensional tunnelling process and the basement excavation process are modelled using step-by-step approaches through the successive removal and installation of the solid and structural elements, respectively. Furthermore, following the field observations, the storminduced water pressure in the existing tunnel is taken into consideration and three further small-scale pit excavations without support installation in the sidewall of the basement towards the tunnel are also performed in the numerical modelling process. The obtained results are discussed in comparison to the observed failures at the construction site, to highlight the deformation and failure mechanisms induced by the excavations and stormwater and to examine the trend of the damage and collapse of the tunnel wall and its support system. It is concluded that although the collapse of the tunnel wall is comprehensively the result of nearby basement excavation before and after the heavy rainfall, the storm-induced water pressure is the main factor resulting in the final collapse of the tunnel wall. Further excavations of three small pits only have relatively slight effects on the instability of the tunnel. The well-developed finite element method provides a valuable tool for the study of the stability of shallow tunnels in the presence of nearby excavations under various conditions.
\end{abstract}

Keywords. Numerical modelling; tunnelling; ground excavation; ground-structure interaction.

\section{Introduction}

The demand to build more facilities for the support of urban cities has been emerging along with the development of modern society. Many of these facilities are constructed in the presence of existing structures such as buildings or shallow tunnels, which may impose significant impacts on these structures and, in turn, raise the associated risk potential during the construction process. Hence, the analysis of excavation-induced ground deformation and stress redistribution is imperative during the design of new facilities in urban cities.

The impact of excavation on adjacent structures has been studied by means of various research methods, among which physical model test [1-3] and field monitoring [4-7] not only present realistic and cogent results but also provide valuable data for selecting input parameters in numerical simulation or validating and calibrating numerical models. By conducting a series of experimental model tests, Choi and Lee [2] quantified the excavation-induced tunnel displacement and the associated crack propagation in the

*For correspondence

Published online: 23 July 2019 presence of an adjacent existing tunnel, indicating that the increase of either the distance between tunnels or the earth pressure coefficient facilitates the stability of the new tunnel. $\mathrm{Ng}$ et al [3] performed several 3D centrifuge tests to investigate the mechanism of basement-tunnel interaction in dry sand, from which the variations of settlements, influence zones and strains were well depicted. Due to the constraints of complexity and budget, large-scale physical model tests on excavation-induced ground-structure interactions have not been conducted extensively. By contrast, the implementation of field monitoring to investigate the effect of excavation on existing structures has been adopted more often as it can be achieved during the practical construction process. Sharma et al [5] presented the results of monitoring the deformations of two parallel tunnels in Singapore in the presence of a nearby large excavation, which indicated that the stiffness of the tunnel lining markedly affects the distortion and movement of the tunnel. Tan et al [7] investigated the responses of twin shield tunnels in an existing metro line to an adjacent oversized deep excavation and the different deformation and displacement patterns of these two tunnels were discussed. Other studies have shown that the structure stiffness has 
non-negligible effect on the ground movement induced by adjacent tunnel excavation $[4,6]$.

The advance of computational techniques has facilitated a rapid expansion in the availability of research on the excavation-induced ground-structure interaction, especially by means of finite element method since such problems usually happen at shallow depth in soft ground. Some 2D finite element analyses of excavation were conducted taking into account of the existence of adjacent structures [8-11]. Potts and Addenbrooke [8] conducted research on the influence of existing structures on tunnelling-induced ground movement and their results led to a modification to the green-field settlement trough induced by surface structures. Zheng and Wei [10] investigated the response of an existing tunnel to an overlying pit excavation and demonstrated that the tunnel embedded depth and the distance between the tunnel and the diaphragm wall play a dominant role in the deformation pattern of the tunnel. Moreover, in the past few decades, the prevalence of 3D finite element modelling has enabled researchers to conduct more complicated and comprehensive studies involving the introduction of structure stiffness, self-weight and geometry into numerical simulation [12, 13]. Subsequently, a number of studies based on 3D numerical modelling have been presented, with the excavation-induced ground-structure interaction being analysed from different perspectives. These include the influences of field stress, construction method and excavation support system [14-17], the effects of various properties of structure itself [18-20] and the impact of the relative positioning of the excavation and the existing structure [21-23]. According to the full 3D FEM modelling analysis conducted by Mroueh and Shahrour [18], overestimation of internal forces in structural members occurs due to the neglect of structural stiffness while underestimation of forces induced by tunnel excavation occurs due to the neglect of the self-weight of building. Coupled with elastoplastic material models, Liu et al [14] presented a full 3D FEM modelling analysis using ABAQUS and TUNNEL3D to investigate the effects of driving a new tunnel on the existing tunnel support systems. It was indicated that the influence highly depends on the location of the new tunnel and a sequence to quantify the level of adverse effects on the existing support systems induced by the new tunnel construction was proposed in this study. By carrying out a 3D finite element analysis, Yoo [21] proposed that the effect of a pilesupported bridge construction on an existing tunnel could be ignored if the distance between the tunnel lining and the pile tip exceeds the tunnel diameter for a centrally loaded tunnel and half the tunnel diameter for an eccentrically loaded tunnel, respectively.

It is worth noting that in $2 \mathrm{D}$ numerical simulation, the interaction between the excavation and the nearby tunnel is normally assumed to be a plane strain problem, which does not represent the reality of strain occurring at the centre of the excavation unless the excavation length along the longitudinal direction of the tunnel is at least nine times of the excavation depth (Shi et al [22]). Furthermore, the wall stability of a tunnel under the combined influence of stormwater and an adjacent basement excavation has been rarely investigated, which is a task worthy of study using 3D finite element method. In this paper, a full three-dimensional finite element model using a Drucker-Prager elastoplastic constitutive law is built for the analysis of such a construction site. Its scope consists of an excavation for the purpose of installing basement floors for the new structure, with one side of the excavation in close proximity to an existing tunnel. After the addition of storm-induced water pressure in the tunnel, further excavations of the basement and of three small pits adjacent to the existing tunnel finally lead to the collapse of the tunnel wall. The displacement and failure mechanisms of the tunnel as well as the factors that resulted in its final collapse are presented in this paper in the context of the simulation results and their comparisons with field observations.

\section{Site details}

The site of interest is located in the city centre of Hobart, Capital of Tasmania, in Australia. On July $27^{\text {th }}, 2016$, the wall of Hobart rivulet tunnel adjacent to ongoing excavation works at the Myer construction site collapsed, resulting in flooding and extensive damage to the site itself as well as the surrounding structures (figure 1). This excavation work was part of the redevelopment of the Myer shopping mall in the CBD of Hobart, with the existence of a nearby tunnel known as "Hobart rivulet tunnel" that was initially built with concrete invert and brick-lined crown and had been in service for almost two hundred years. The Hobart rivulet is part of the catchment of the Derwent river and flows through and underneath the city. When originally constructed, it was entirely exposed in the open-air. With the development of the urban city, the rivulet has been gradually enclosed by the new structures constructed along its perimeter, with the surrounding walls consisting of stone slabs and bricks. Concrete support frames were installed at regular intervals to increase the strength of the rivulet tunnel. The construction works at the site at the time of the collapse involved the installation of mass concrete underpins of $0.5 \mathrm{~m}$ width in a hit-or-miss sequence to reinforce the existing walls of the rivulet tunnel and support a basement excavation $40 \mathrm{~m}$ wide, $40 \mathrm{~m}$ long and $8 \mathrm{~m}$ deep (figure 2). Several small-scale pit excavations were made beneath the tunnel to conduct the undercutting work, after which the collapse occurred in a short time interval. At the point of failure, the dimension of the horseshoe shape rivulet tunnel was gauged as $4 \mathrm{~m}$ high by $4 \mathrm{~m}$ wide and the distance between the top of crown and the ground surface was $1 \mathrm{~m}$. 

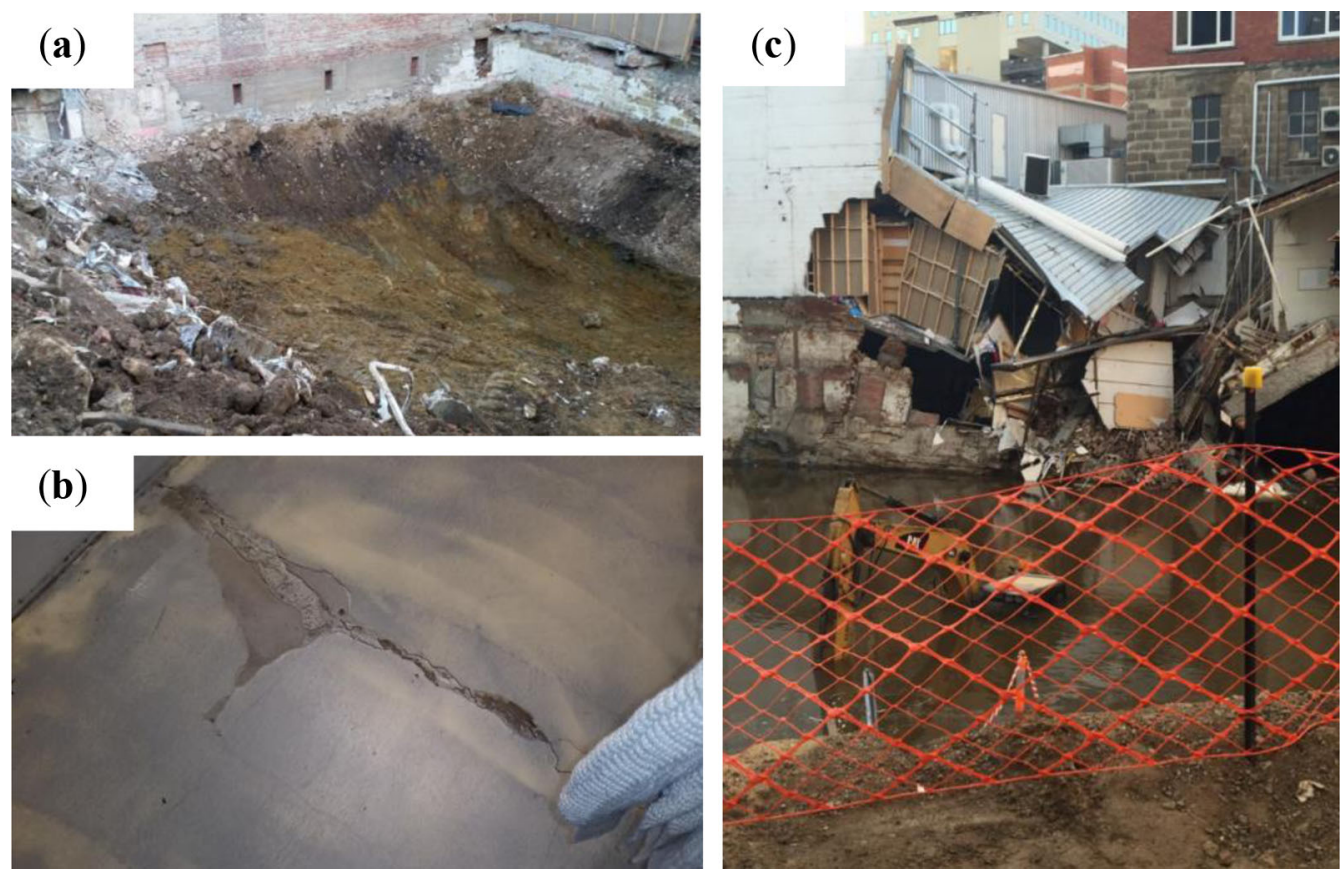

Figure 1. Photographs of the site: (a) The western end of the site during construction. (b) A representative crack in a store next to the site during construction. (c) The final collapse of the site and the surrounding structures.

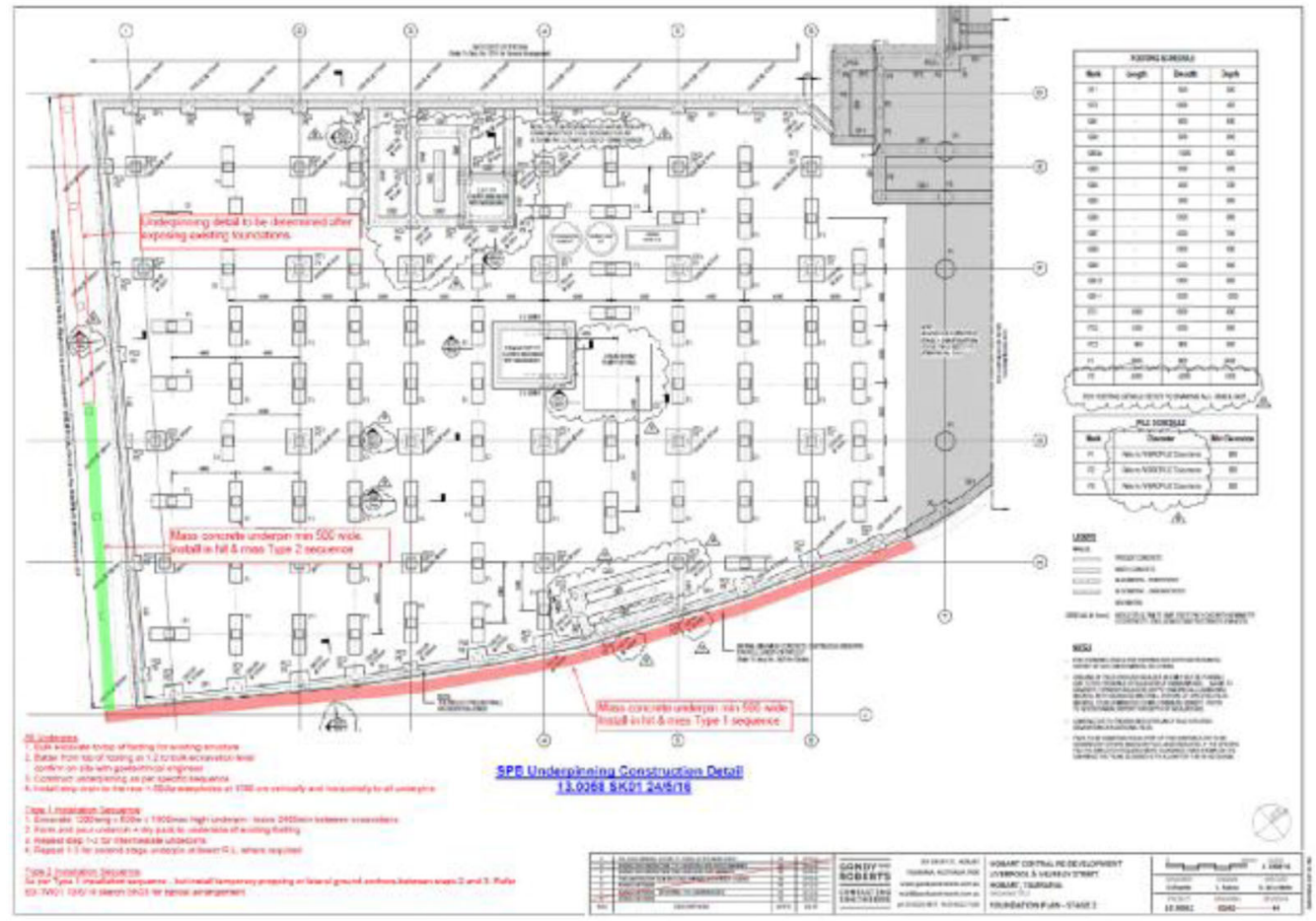

Figure 2. Details of the construction site (plan view from Gandy and Roberts 2016). 


\subsection{Major geological and hydrological considerations}

The predominant characteristic geological feature of the Sandy Bay catchment in Hobart is Jurassic Dolerite, which occurs in the lower catchment involving the urban areas as well as the southern edge of the Waterworks Reserve (Davies [24]). Throughout the city, the geological composition consists of two major varieties: sediment characterised by black, high plasticity overlying clay which abruptly transits into slightly weathered Dolerite, and sand overlying very sandy clay, transitioning into sandstone and mudstone. According to the Mineral Resources Tasmania's (MRT) database, at the city centre, the geological profile broadly consists of gravel-clay mix and sandy clay with boulders extending $10 \mathrm{~m}$ below the ground surface, then sandstone and mudstone from moderate to low weathering conditions for the next $10 \mathrm{~m}$ depth, with the following $20 \mathrm{~m}$ layer recognized as fresh rock consisting of sandstone and mudstone, and finally at depths of more than $40 \mathrm{~m}$ the underlying Dolerite. For the site of interest, since the depth of the excavation and the foundations of adjacent structures were relatively shallow, the underlying Dolerite with high depth was considered irrelevant to the behaviour of the site during excavation.

Hobart is a city located in the path of several natural streams and, consequently, the Hobart rivulet receives water supplied by these resources. In addition, the rivulet plays a significant role in stormwater management in terms of removing surplus water from residential and commercial properties to avoid flood damage, which indicates that the flow reaches its maximum volume during major rainfall events when running below the CBD. Before excavation, the water volume in the rivulet tunnel was relatively small and was considered as imposing no obvious impact on the tunnel walls. However, before the rivulet tunnel collapse, Hobart had experienced a heavy rainfall, which imposed a significant increase in the stress imposed on the rivulet tunnel. In this case, it may be unnecessary to calculate the maximum flow rate of a historic storm since this study is not intended to model the entire stormwater network in Hobart. Instead, the storm-induced water pressure on the base and sidewalls of the rivulet tunnel near the end of the major flow corridor of the catchment during a storm of similar magnitude to the one which occurred prior to the collapse is the factor to be determined.

\subsection{Site investigation methods}

It was unfeasible to obtain geological information directly from the construction site since it had totally collapsed and information related to it was confidential and not disclosed to the public. Because of this, the MRT database of the Tasmanian Government was used to investigate the available data points near the site of interest, from which 40 boreholes were located in a distance of less than $500 \mathrm{~m}$ from the site with 10 of these falling within $200 \mathrm{~m}$. It was found that many of these borehole locations could be connected in a manner that intersected the construction site. By taking sets of these points and combining them with available data on the surface level of the site prior to the excavation, cross sections through the site were able to be produced on the basis of the changes in the depth of geological strata between the boreholes. By repeating this process multiple times for different cross sections through the site until the obtained values fitted with the information available in all cross sections, corrections for non-typical geological features near individual boreholes were achieved and thus the accuracy of the predicted depths of the geological strata at the site increased.

For the calculation of the maximum water pressure induced in the rivulet tunnel by the storm over the site in the night before the collapse happened, rainfall data from several weather stations located in or near the Hobart rainfall catchment taken during or directly proceeding the collapse were collected and rational method flow volume modelling was implemented based on known rainfall characteristics of the Hobart catchment, including average rainfall intensity, storm duration, ten-year discharge coefficient, peak flow rate for Average Exceedance Probability (AEP) of 1 in y years and height of flow, etc.

\subsection{Site investigation results}

The physical and mechanical parameters of the geological materials at the construction site are listed in table 1, which have been extrapolated from borehole test results close to the site. In table 1, the strata are classified as four layers from the upper sediment to the underlying fresh rock while the bottom layer of Dolerite is neglected due to its high depth.

By conducting a full rational method derivation of the rainfall data collected from weather stations located in the Hobart rainfall catchment, it was evaluated that for a storm with an average rainfall intensity of $10 \mathrm{~mm} / \mathrm{h}$, the peak flow rate at the site could reach $23 \mathrm{~m}^{3} / \mathrm{s}$. By distributing the induced pressure over the invert and the sidewalls of the rivulet tunnel using the rational method and taking the weight of water into account, it was calculated that a pressure of $63.9 \mathrm{kPa}$ was imposed per linear metre at the base along the longitudinal direction of the tunnel while the water pressure at each sidewall of the tunnel was evaluated as $23.3 \mathrm{kPa}$ per linear metre.

\section{Numerical model and method}

As mentioned in section 1, the analysis could not be simplified to a two-dimensional plane strain analysis for an accurate reproduction of the real deformation and 
Table 1. Physical-mechanical properties of the geological material at site.

\begin{tabular}{|c|c|c|c|c|c|c|}
\hline Geological material & Depth (m) & $\begin{array}{l}\text { Unit weight } \\
\qquad\left(\mathrm{kN} / \mathrm{m}^{3}\right)\end{array}$ & $\begin{array}{l}\text { Friction } \\
\text { angle }\left(^{\circ}\right)\end{array}$ & $\begin{array}{l}\text { Cohesion } \\
\qquad(\mathrm{kPa})\end{array}$ & $\begin{array}{l}\text { Elastic modulus } \\
(\mathrm{MPa})\end{array}$ & $\begin{array}{l}\text { Poisson's } \\
\text { ratio }\end{array}$ \\
\hline Gravel-clay mix & 0 to -6.2 & 16 & 20 & 16 & 60 & 0.2 \\
\hline Sandy clay with boulders & -6.2 to -9.9 & 18 & 20 & 30 & 100 & 0.3 \\
\hline $\begin{array}{l}\text { Sandstone/mudstone } \\
\text { (moderate/low weathering) }\end{array}$ & -9.9 to -18.2 & 26.5 & 30 & 6000 & 18000 & 0.25 \\
\hline Sandstone/mudstone (fresh rock) & Below -18.2 & 26.5 & 30 & 8000 & 24000 & 0.2 \\
\hline
\end{tabular}

failure mechanisms. Therefore, a full three-dimensional modelling is introduced in this study, taking into account the tunnelling and basement excavation processes, the installation of support system for the tunnel and the interactions among different components of the model. The finite element-based program ANSYS (ANSYS [25]) is regarded as a robust means to deal with such issues and thus is selected as the numerical tool for the simulation of the site.

\subsection{Geometrical and finite element models}

Figure 3 depicts the three-dimensional geometrical and finite element models of the construction site. The size of the whole model is marked in figure 3(a) and the finite element mesh (figure 3b) involves 198,000 eight-node isoparametric hexahedral elements with 207,571 nodes and 3,600 four-node shell elements with 5881 nodes to model the behaviour of geological material and support system, respectively. The existing tunnel is modelled with a length of $80 \mathrm{~m}$ and supported using concrete lining with a thickness of $0.4 \mathrm{~m}$. Figure 4 presents the two-dimensional geometry of the horseshoe-shaped tunnel. As can be seen in figure 4, the existing tunnel has a cross section composed of a rectangle in $3 \mathrm{~m}$ high by $4 \mathrm{~m}$ wide and an arched roof with a curvature radius of $2.5 \mathrm{~m}$.

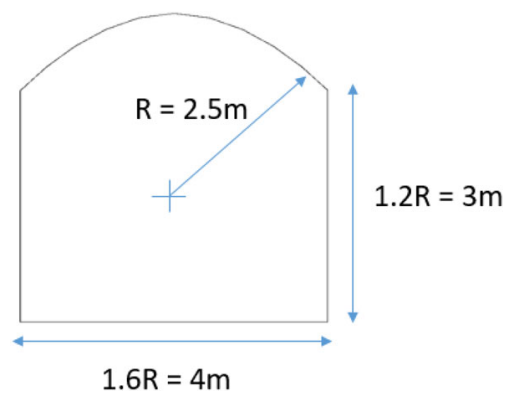

Figure 4. 2D geometry of the horseshoe shape tunnel.

\subsection{Modelling of excavation and support phases}

Both the tunnel and basement excavations are modelled using step-by-step approaches. For the rivulet tunnel, successive removal of solid elements (soft rock) in front of the tunnel face while successively installing shell elements (concrete lining) behind the tunnel face are simulated in the z-direction of the model with each step progressing by a distance of $8 \mathrm{~m}$. Although the actual formation process of the rivulet tunnel differed from this procedure, the simulation of the tunnelling process is important to ensure that the stress distribution surrounding the rivulet tunnel can be reproduced. During the calculation process, at the first

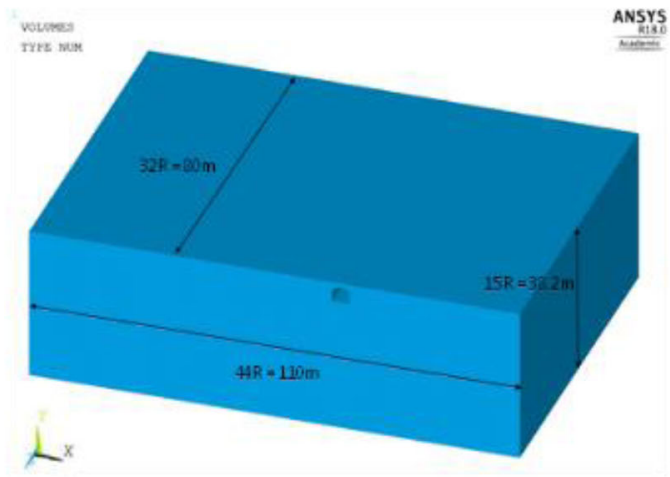

(a)

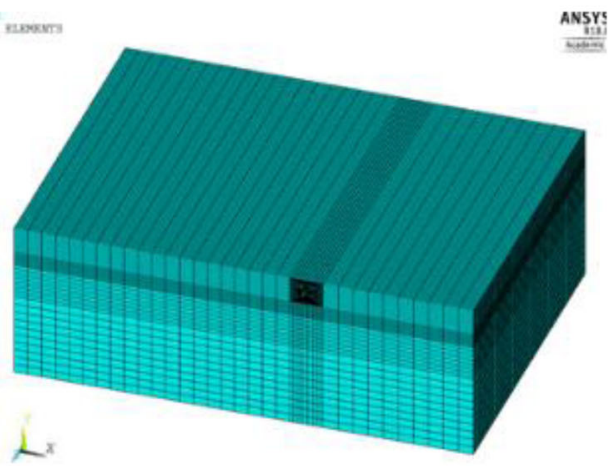

(b)

Figure 3. Numerical model: (a) 3D geometry of the site; (b) 3D finite element model. 
analysis step, the support elements are deactivated, then at the following 10 steps, they are subsequently activated one step after the rock elements are deactivated, i.e., $8 \mathrm{~m}$ behind the tunnelling advancing surface, to simulate the tunnelling and support installation processes simultaneously.

For the basement excavation, firstly successive removal of solid elements (soft rock) along the y-direction of the model is conducted in two steps to excavate the first layer of ground. After the addition of water pressure in the tunnel, a further excavation step is carried out in the second layer of ground to finish the excavation of the $40 \mathrm{~m}$ wide, $40 \mathrm{~m}$ long and $8 \mathrm{~m}$ deep basement (figure 5a), where the distance between the sidewall of tunnel and the sidewall of the basement excavation is $2 \mathrm{~m}$. Further excavations of three small pits are then performed in the sidewall of the excavated basement towards the tunnel (figure $5 b$ ). The middle pit has a size of $2 \mathrm{~m}$ wide by $1 \mathrm{~m}$ high while the two side pits are both $1 \mathrm{~m}$ wide by $1 \mathrm{~m}$ high and the span between the side and middle pit is $3 \mathrm{~m}$. The top of each pit is at a distance of $6.5 \mathrm{~m}$ below the ground surface and the pit excavation extends $4 \mathrm{~m}$ towards the tunnel with no support system installed.

\subsection{Initial stresses, boundary conditions and loads}

The initial stress field is obtained at the first analysis step by applying the gravity force on the model with no support element activated and no solid element excavated. In the designed model, the front and back surfaces are fixed in the $\mathrm{z}$-direction and the left and right surfaces are fixed in the $\mathrm{x}$-direction. The bottom surface is fixed in the y-direction while the top surface is free in all directions. Since the geometry of the model is approximately 44 times the tunnel size in the $\mathrm{x}$-direction, 15 times in the y-direction and 32 times in the z-direction with precise mesh grids adopted in this case, these boundary conditions have no influence on the subsequent numerical simulations.

(a)

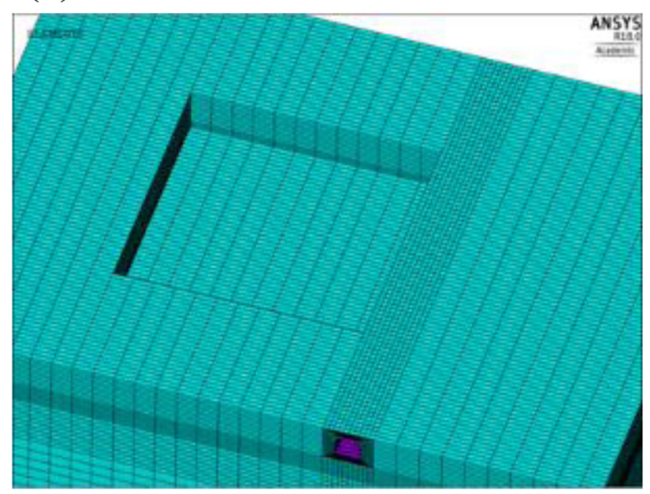

For the design loads, the calculated water pressures of $63.9 \mathrm{kPa}$ and $23.3 \mathrm{kPa}$ are applied on the bottom and the sidewalls of tunnel, respectively, to simulate the effects of stormwater on the tunnel structure after the modelling of the first two basement excavation steps while the loads imposed by the adjacent structures are not taken into consideration.

\subsection{Elastoplastic constitutive models}

The Drucker-Prager elastoplastic constitutive law is adopted to model the behavior of the various geological materials. As shown in figure 6, the Drucker-Prager criterion on the meridional plane and the associated function are given in Eq. (1):

$$
f(\rho, s)=\sqrt{6} \alpha \rho+s-\sqrt{2} k=0
$$

where $\rho$ is the hydrostatic stress vector magnitude, $\mathrm{s}$ is the deviatoric stress vector magnitude, and $\alpha, \mathrm{k}$ are material parameters. The physical-mechanical properties of the

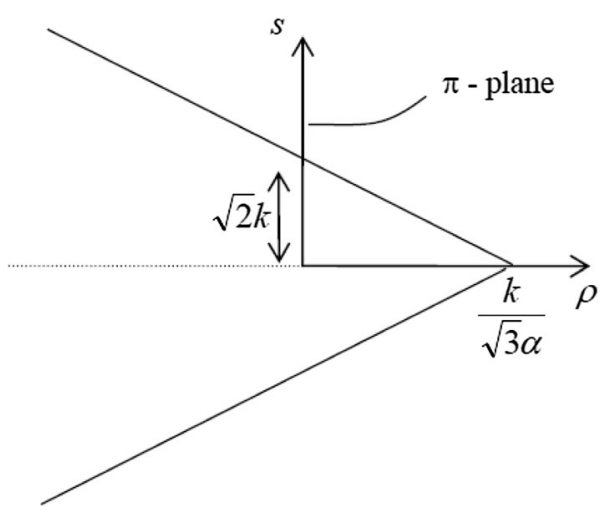

Figure 6. The Drucker-Prager criterion on the meridional plane (Kelly [26]).

(b)

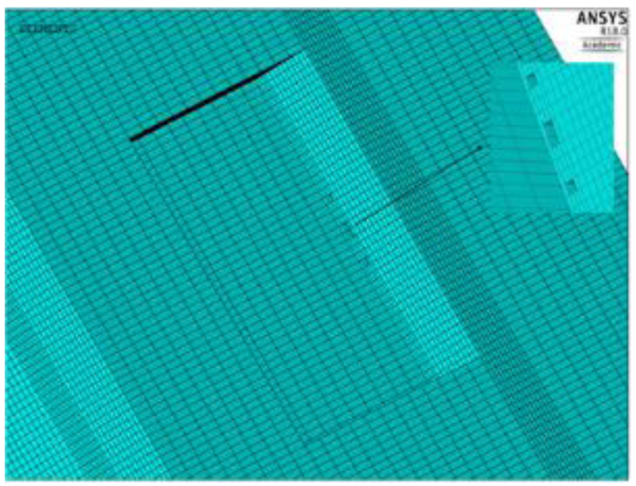

Figure 5. Finite element model: (a) 3D finite element modelling of basement excavation; (b) 3D finite element modelling of further pit excavation. 
geological material at site are listed in table 1 in section 2.3 and the behaviour of the concrete lining is regarded as elastic perfectly-plastic with a density of $2000 \mathrm{~kg} / \mathrm{m}^{3}$, a Young's modulus of $12000 \mathrm{MPa}$, and a Poisson's ratio of 0.3 .

\section{Numerical results and analyses}

The effects of basement excavation, stormwater and further pit excavation on the stability of the tunnel wall are analysed here, in terms of the displacement of the tunnel support system, the changes of stresses around the tunnel and the patterns of damage zones in the model. It is noteworthy that throughout this paper, tensile stress and strain are taken as positive while compressive stress and strain are regarded as negative.

\subsection{Displacement of the tunnel support system under the impact of excavations and stormwater}

In this section, the impacts of the basement excavation, the storm-induced stress and the further pit excavation on the rivulet tunnel are analysed by first investigating the variations of horizontal and vertical displacement patterns at a monitored plane during the construction process and then by investigating the variation of total displacement at several locations on the crown and sidewall of the tunnel support system. As can be seen from figure 7(a), the central transverse section of the model at XY-plane is selected as the monitored plane due to the symmetry of the numerical model in the z-direction. As the emphasis of this study is on the investigation of the failure mechanism of tunnel, a more specific monitored plane only including the ground around the tunnel is allowed to intercept this transverse section to observe the horizontal and vertical displacement patterns in various construction steps, as shown in figure 7(a).
For the variations of horizontal and vertical displacement patterns around tunnel at the chosen monitored plane during the construction process, as presented in figure 8, the horizontal displacement pattern in each figure is listed on the left and the vertical displacement pattern is shown on the right. Following the excavation of tunnel and installation of support system (figure 8a), due to the effectiveness of strengthening provided by the concrete support, the tunnel walls only experience slight horizontal movements while unavoidable ground settlements proceed at the tunnel crown and invert. Then after the first two steps of basement excavation (figure 8b), the surrounding ground of tunnel moves towards the basement side while the vertical displacement pattern around tunnel has only been slightly influenced. With the addition of water pressure (figure 8c), the tunnel wall close to the basement shows a more obvious trend of movement towards the excavation site while the movement of the tunnel wall far from the basement has been constrained due to the balancing stress from water pressure. Meanwhile, the left part of the monitored plane also experiences more apparent vertical displacements as the ground instability at this side has been continuously increasing under the stress effects of the existing excavation site and the water pressure towards the site. This phenomenon becomes more distinct after the further basement excavation (figure 8d) and particularly after the excavation of the small pits in the second layer of ground under the left part of the monitored plane (figure 8e). For the horizontal displacement profile after the final basement and pit excavations, it can be observed that the maximum displacement region is more concentrated in the bottom area of the basement sidewall in the first layer of ground and the tunnel wall close to the basement suffers from evident disturbance during these two construction steps while the displacements at the tunnel wall far from the basement are still restrained in a small movement range. Thus, it is reasonable to conclude that the construction process has a significant effect on the horizontal and vertical displacement profiles at the tunnel wall and the ground close to the basement while the tunnel (a)

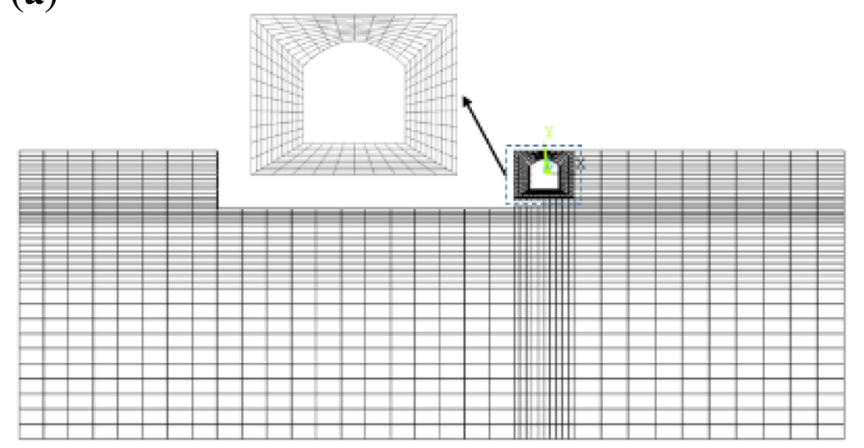

(b)

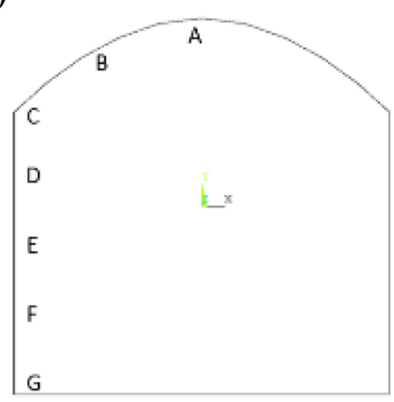

Figure 7. Monitored plane and locations from the numerical model: (a) monitored plane; (b) monitored locations. 

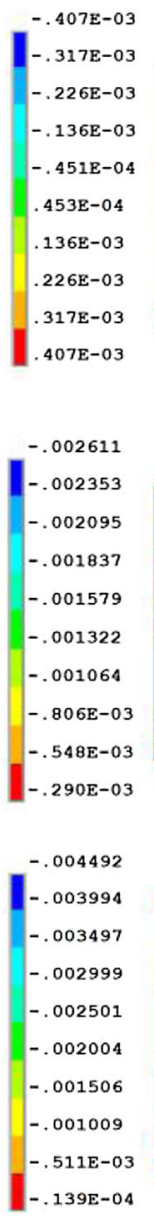

$-.006037$

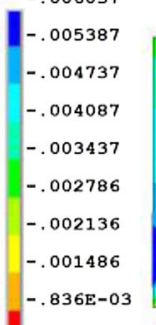

$-.186 \mathrm{E}-03$

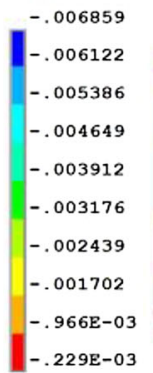

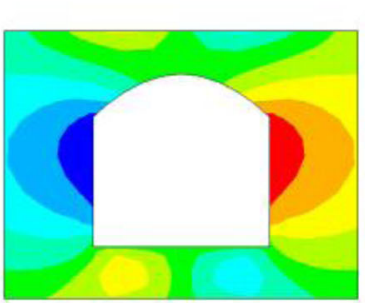

(a)
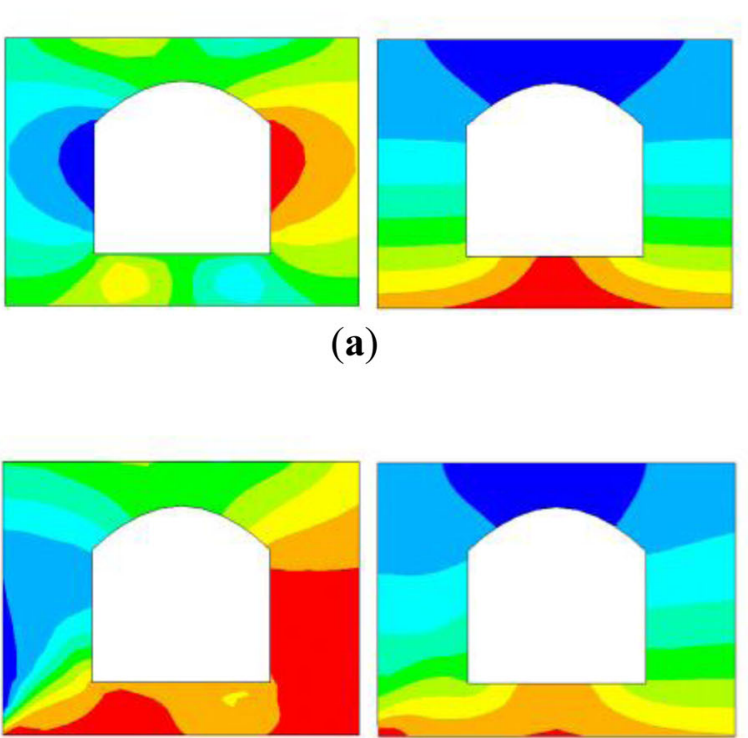

(b)
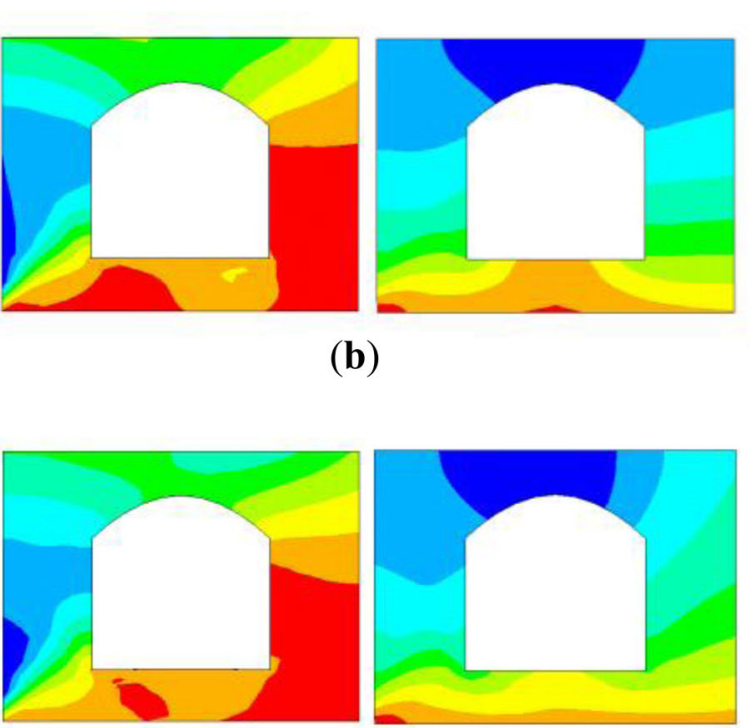

(c)
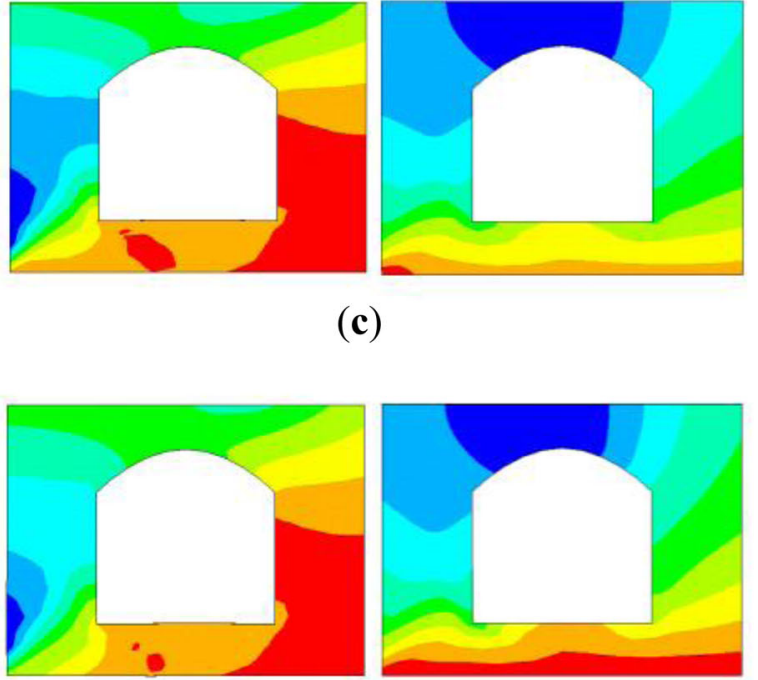

(d)
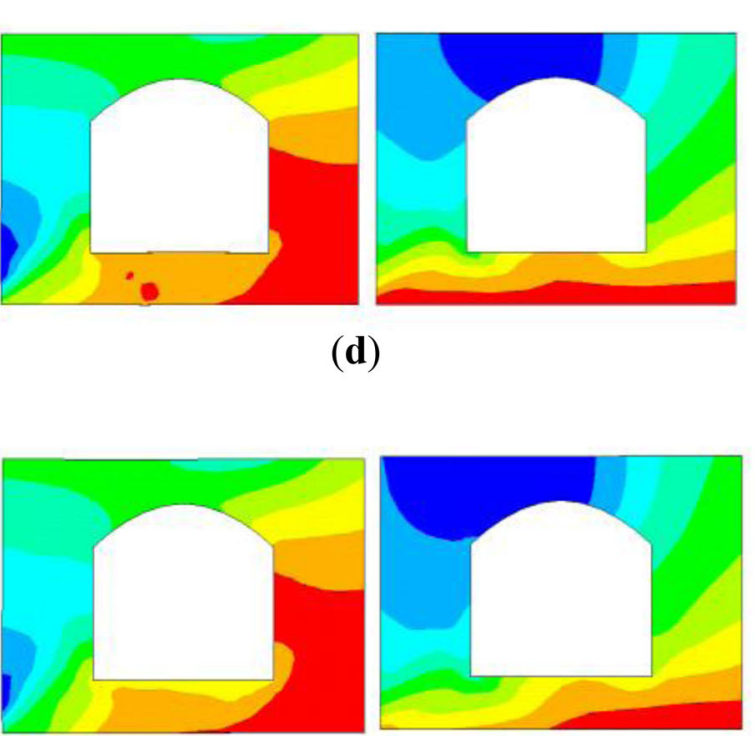

(e)
$-.00931$

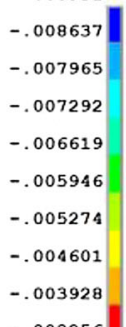

$-.003256$

$-.010086$

$-.009251$

$-.008416$

$-.007582$

$-.006747$

$-.005912$

$-.005077$

$-.004243$

$-.003408$

$-.002573$

$-.012939$

$-.011815$

$-.01069$

$-.009565$

$-.00844$

$-.007315$

$-.00619$

$-.005065$

$-.00394$

$-.002816$

$-.013847$

$-.012804$

$-.01176$

$-.010717$

$-.009673$

$-.008629$

$-.007586$

$-.006542$

$-.005498$

$-.004455$

-.015125
-.013951
-.012777
-.011603
-.010429
-.009255
-.008081
-.006907
-.005733
-.004559

Figure 8. Horizontal and vertical displacement patterns around tunnel at the monitored plane in various construction steps (unit: $\mathrm{m}$ ): (a) Step 11: after the finish of tunnel excavation and support installation; (b) Step 13: after the first two steps of basement excavation; (c) Step 14: after the addition of storm-induced water pressure; (d) Step 15: after the final step of basement excavation; (e) Step 16: after the completion of further pit excavation. 
wall far from the basement experiences relatively slight impact due to the strengthening effect of the storm-induced pressure at this side.

For the analysis of variations of total displacement at monitored locations during the construction process, as depicted in figure 7(b), seven monitored locations in the support system at this plane have been selected from the top of the tunnel crown (A) to the bottom of the tunnel wall close to the basement $(\mathrm{G})$. The monitoring of symmetric locations at the other side of the tunnel wall has been omitted since the above displacement patterns indicate that the tunnel wall close to the basement undergoes more severe influence and from field observation it is known that the collapse of the site was initiated from the tunnel wall close to the basement and thus the investigation of the variations of displacement at the collapsed side is enough for this back analysis.

The total displacement at each analysis step after the excavation of the tunnel and installation of support is recorded in figure 9 to investigate the extent of the effect of each construction step. Each analysis step corresponds to the construction step with the same sequential number and the meaning of each step has been listed in the annotation of figure 8. In finite element analysis each analysis step is achieved by dividing the loading into several load steps. For instance, the first step of basement excavation (Step 12) is performed through 7 load steps and the further excavation of the three small pits (step 16) is carried out through 9 load steps. As a result of this, each analysis step in figure 9 designates the final load step in each corresponding construction step.

Figure 9 indicates that the patterns of the variation of total displacement at these seven locations are similar. To be specific, the effect of the first step of basement excavation on the tunnel support system is eliminated by the elastic rebound of the first layer of soft rock after tunnel excavation and support installation while the second

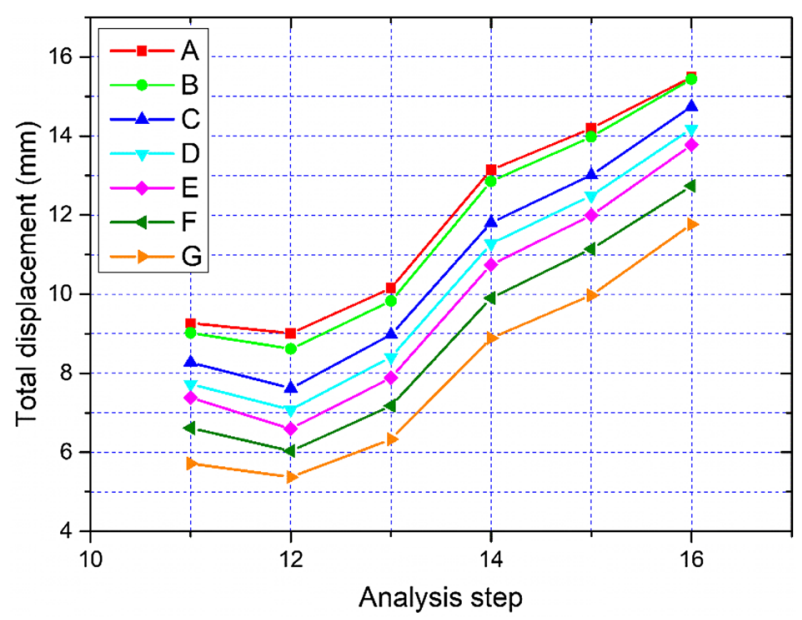

Figure 9. Effects of excavations and stormwater on the total displacement of the support system at the monitored locations. basement excavation step apparently facilitates the increase of displacement in the support system. From steps 13 to 14 it is observed that the storm-induced water pressure has the most obvious effect on all monitored locations compared with any other steps. In contrast with the second excavation step, the final step of the basement excavation and the further excavation of three small pits have slightly less influence on the variations of displacement although still raise the instability of the tunnel support system. Percentage increments of the total displacement induced by excavations and stormwater from location $\mathrm{A}$ to $\mathrm{G}$ are calculated as $67.24 \%, 71.16 \%$, $78.15 \%, 83.62 \%, 86.57 \%, 92.59 \%$ and $105.90 \%$, respectively, revealing that the impacts of excavations and stormwater on the support system become more severe when approaching the bottom of the tunnel wall, which further indicates that the damage zones are more likely to initiate near this area. Although the final total displacement at the bottom of the tunnel wall is still the smallest among the monitored locations, the significant raise of the instability at this bottom area is a tremendous risk for the whole system, which is able to be verified by the field observation that has been referred to in section 2 .

\subsection{Effects of excavations and stormwater on the changes of stresses around the tunnel}

The effects of excavations and stormwater on the changes of stresses in the surrounding ground of the tunnel are quantitatively evaluated in this section from several locations at the centre of the numerical model depicted in figure 10. Figure 11 records the major principle stress (Stress1) and the maximum shear stress (Stress XY) in the surrounding ground at this centre region in various construction steps. The locations of the solid elements in the surrounding ground shown in figure 10 are indicated by the

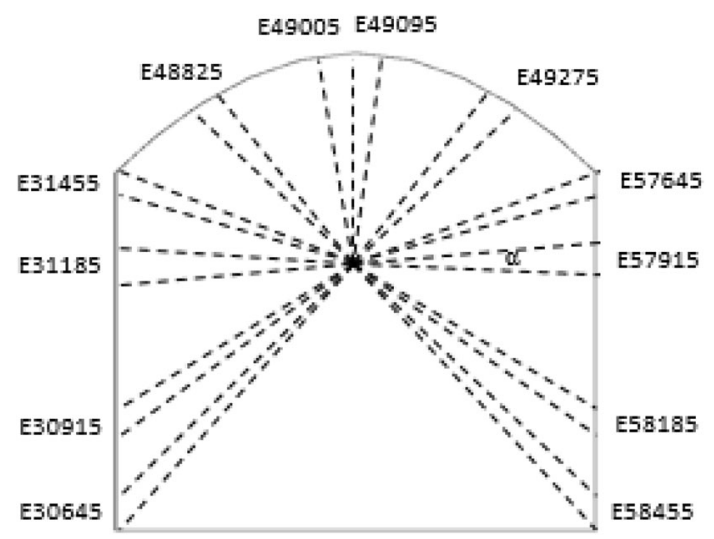

Figure 10. Surrounding ground of tunnel at the centre of the model. 


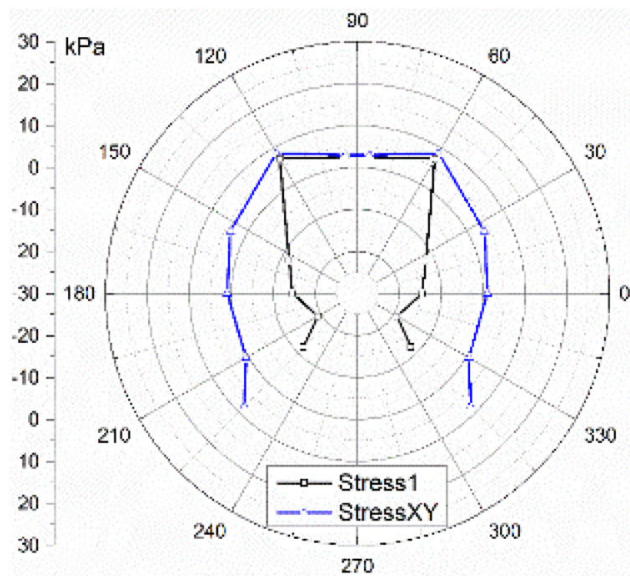

(a)

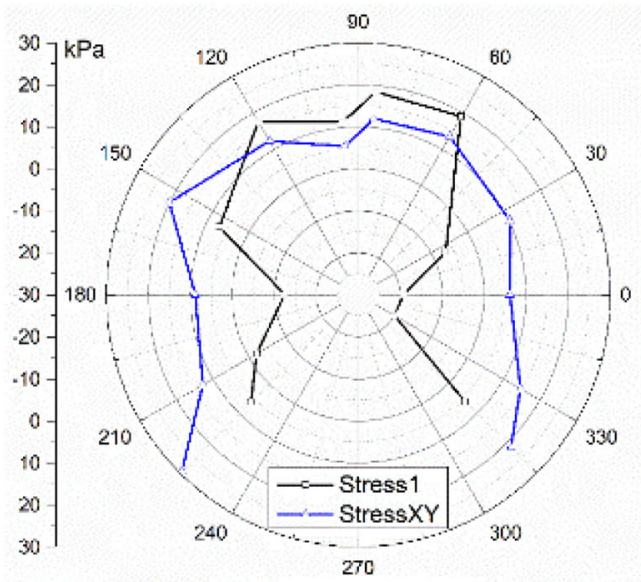

(c)

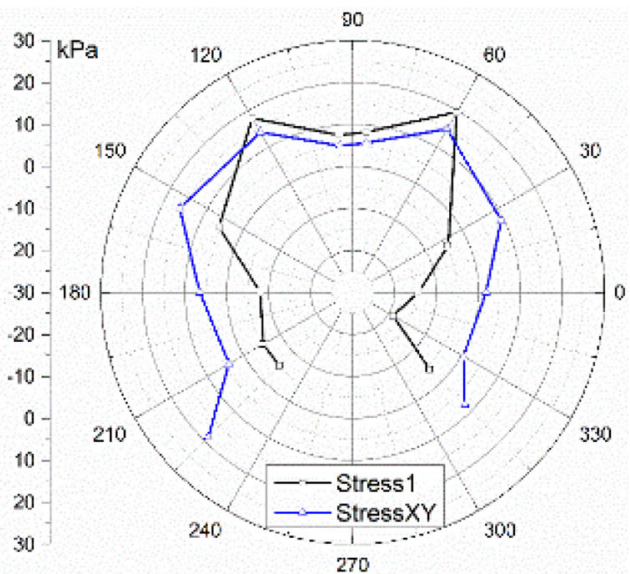

(b)

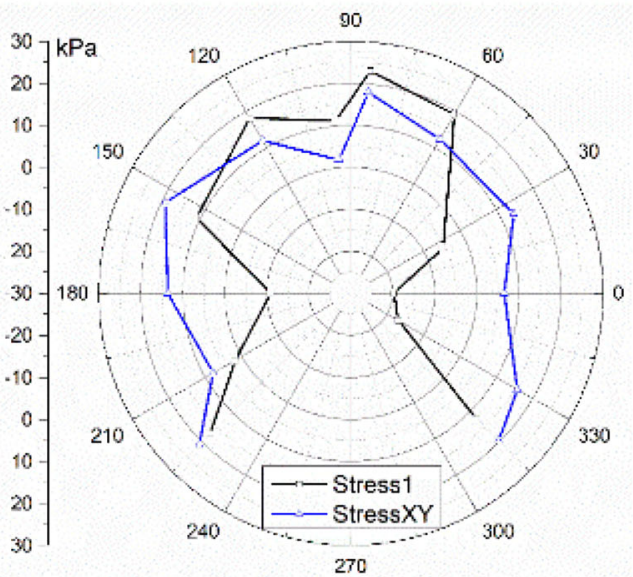

(d)

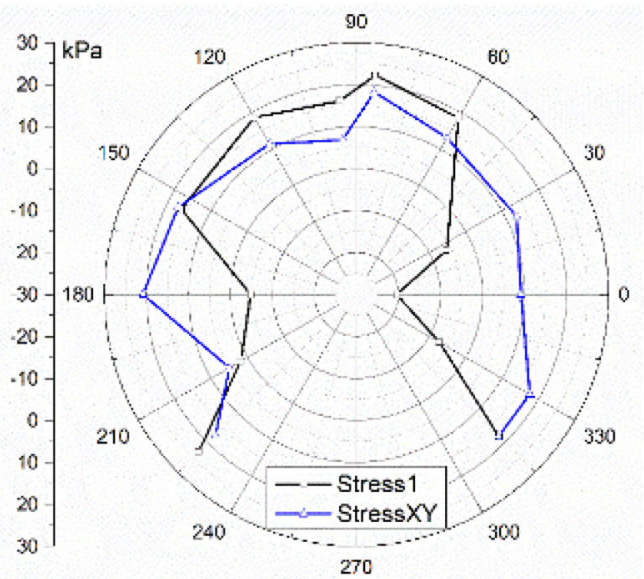

(e)

Figure 11. Stresses in the surrounding ground of tunnel at the centre of the model in various construction steps: (a) Step 11: after the finish of tunnel excavation and support installation; (b) Step 13: after the first two steps of basement excavation; (c) Step 14: after the addition of storm-induced water pressure; (d) Step 15: after the final step of basement excavation; (e) Step 16: after the completion of further pit excavation. 
angle in polar coordinates, where the corresponding relationship between the location and the angle is illustrated in figure 10.

Comparison of figure 11(a) and (b) indicates that the first two steps of basement excavation have a significant impact on the tunnel wall close to the basement and the crown of the tunnel in terms of raising the shear stresses while reducing the initially induced compressive stresses at this tunnel wall, as well as markedly increasing the initially induced tensile stresses at the tunnel crown. With the addition of water pressure (figure 11c), the principle stress mode at the bottom area of the tunnel wall close to the basement has been changed from compressive to tensile and the tensile stresses at the crown top of the tunnel have been further enhanced. It is worth noting that after the addition of stormwater the stress increase at the crown top far from the basement is more severe. The reason for this phenomenon is that during the construction process, the ground above the tunnel crown adjacent to the basement has a tendency to move and fall towards the excavation site, which to an extent eases the stresses acting on the tunnel crown at this side. The final step of basement excavation (figure 11d) has certain effects on the increases of principle stresses at the bottom areas of both tunnel walls while showing a more obvious impact on the variations of shear stresses at the tunnel wall close to the basement and the tunnel crown. The excavation of small pits (figure 11e) contributes to the decrease of compressive stresses at the middle part of the tunnel wall close to the basement and the increase of tensile stresses at the top and bottom areas of this wall. It is noteworthy that the stress patterns at the tunnel wall far from the basement experience less influence throughout the construction process, with the addition of water pressure that provides supporting effect at this side, which actually enhances the stability of this tunnel wall and reduces the risk of damage initiated from this wall.

The comparisons between different steps indicate that the first two steps of basement excavation and the addition of water pressure are the main factors that influence the variations of stresses in the surrounding ground of tunnel. As the rivulet tunnel is a very shallow tunnel in soft ground, the close excavation triggered the change of stress modes at the top and bottom areas of the tunnel wall close to the basement, then the stress induced by stormwater further acted on these areas. Although the final tensile stress values in the surrounding ground are relatively small, the inadequate strength of the soft ground at such a shallow distance could still result in damage and collapse at these areas. Combined with the obtained results in the above section, it is clear that the bottom area of the tunnel wall close to the basement is the most conspicuous weak area, experiencing obvious variations of displacement and stress, and so the initiatory damage and collapse are most likely to appear at this area.

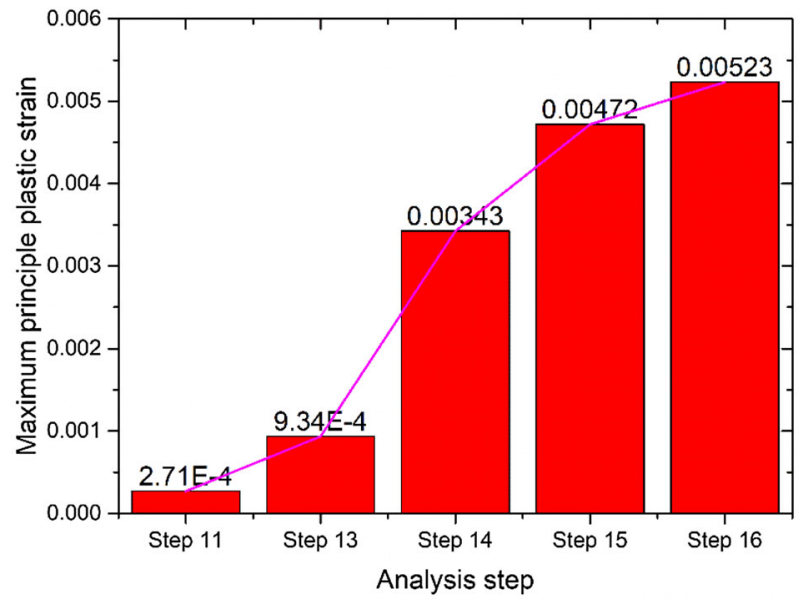

Figure 12. Variation of the maximum principle plastic strain at the surrounding ground of tunnel in various construction steps.

\subsection{Patterns of damage zones in the finite element model}

In order to estimate the effects of the construction operations and the storm-induced stress on the stability of the tunnel and the sidewall of the excavated basement adjacent to the tunnel, the maximum principle plastic strain is evaluated to observe the extent of the impact of each step (figures 12 and 14) and the damage zones at the monitored plane in figure 5(a) are delineated in figure 13 .

The variation of the maximum principle plastic strain at the surrounding ground of tunnel in various construction steps is depicted in figure 12, from which it can be seen that the stability of the surrounding ground has not been apparently affected during the tunnel excavation and support installation process. Then with the excavation of basement, the value of the maximum principle plastic strain has obviously increased. Subsequently, storm-induced water pressure acts on the inside of the tunnel, resulting in a huge increase of the maximum principle plastic strain value at the bottom area of the tunnel wall close to the basement. Whereafter, the further excavations of basement and three small pits have no such apparent influence on the instability of the surrounding ground.

Figure 13 presents the damage zones around the tunnel at the monitored plane (figure 7a) in various steps, indicating that the initiation and propagation of damage zones from the basement sidewall to the tunnel wall induced by the first two steps of basement excavation do not overtly influence the stability of the tunnel wall (figure 13b) until the added water pressure facilitates the extrusion and propagation of damage zones at the bottom area of the tunnel walls. Then these damage zones coalescence at the region between the basement sidewall and the bottom area of the tunnel wall close to the basement (figure 13c) and spread rapidly under the influence of the further basement and pit excavations 


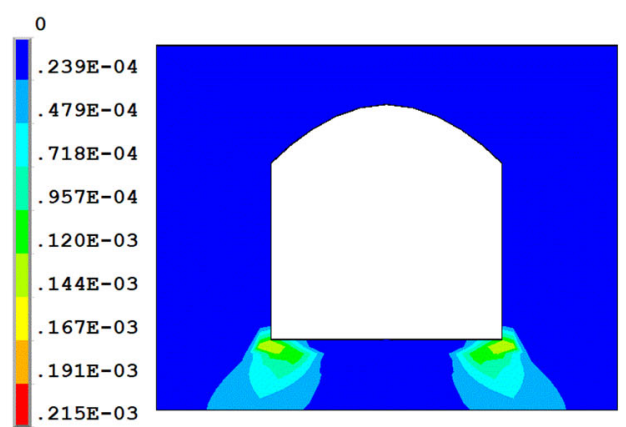

(a)

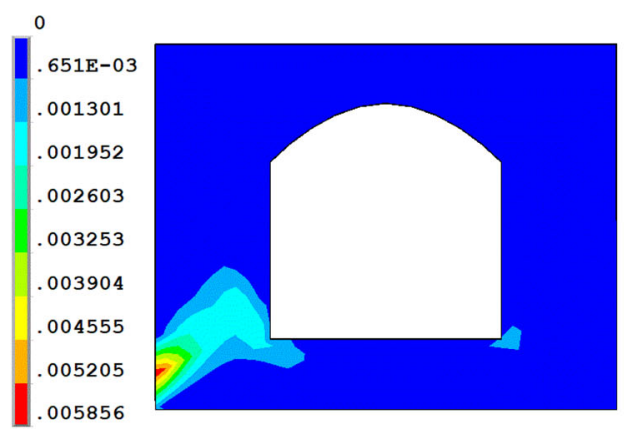

(c)

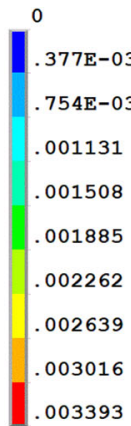

003393

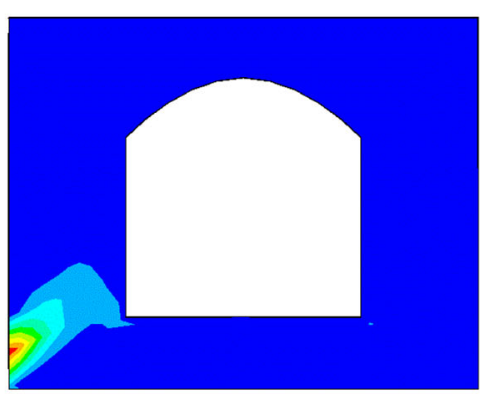

(b)
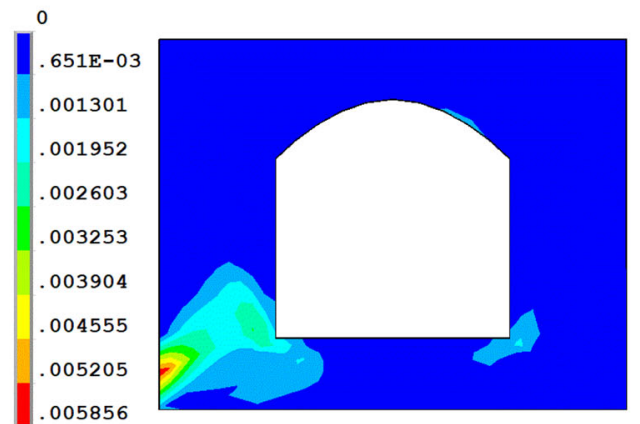

(d)

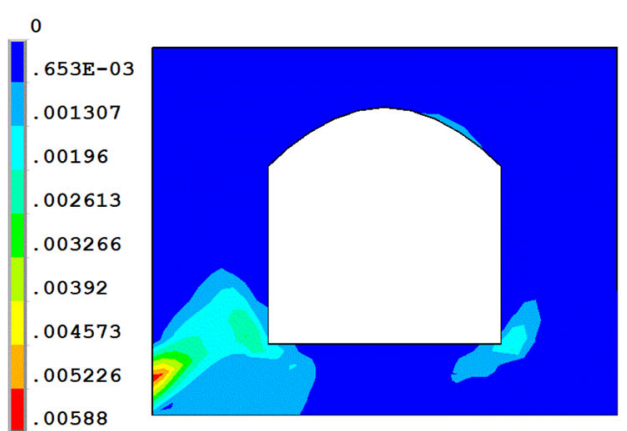

(e)

Figure 13. Damage zones around tunnel at the monitored plane in various construction steps: (a) Step 11: after the finish of tunnel excavation and support installation; (b) Step 13: after the first two steps of basement excavation; (c) Step 14: after the addition of storminduced water pressure; (d) Step 15: after the final step of basement excavation; (e) Step 16: after the completion of further pit excavation.

(figure $13 \mathrm{~d}$ and e). Furthermore, the basement and pit excavations also promote the initiation and propagation of damage zones at the tunnel crown far from the basement (figure 13d and e). This appearance corresponds well with the stress variation phenomenon at this area that has been observed and explained in the above section. Nevertheless, the final damage zone formed at the tunnel crown does not significantly impact the tunnel stability since the plastic strain values in this region are too small compared with those at the bottom area of the tunnel wall.

The numerical results indicate that the first two steps of basement excavation exert the most significant influence on the formation of damage zones and the increase of maximum principle plastic strain at the basement sidewall near the bottom of the first layer of ground while water pressure has the greatest impact on the formation, propagation and coalescence of damage zones at the bottom area of the tunnel wall close to the basement as well as the increase of plastic strain around this bottom region. Combined with the analyses in the previous two sections, it is found out that damage zones appear at locations where variations of displacements and stresses are much higher than other regions. Especially for the bottom area of the tunnel wall, the maximum variations of displacement and stress as well as 


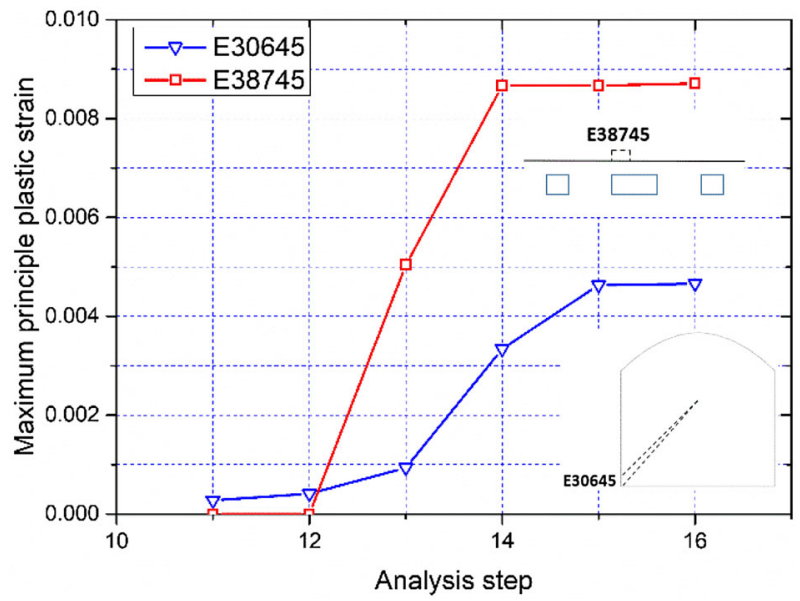

Figure 14. Effects of excavations and stormwater on the surrounding ground of tunnel and the basement sidewall.

the maximum principle plastic strain all occur at this location, indicating that the damage and collapse were exactly initiated from this area.

Figure 14 quantifies the relative effects of excavations and stormwater on the surrounding ground of tunnel and on the basement sidewall in terms of the changes of maximum principle plastic strain during the construction process after the finish of tunnel excavation and support installation. It should be noted that the selected monitored plane is still the plane presented in figure 7(a) and the chosen elements in this plane are E30645 at the bottom area of the tunnel wall close to the basement and E38745 at the sidewall of the basement since the values of maximum principle plastic strain at these two areas reach the peak in these two elements at the plane. It can be easily observed that the second step of basement excavation greatly affects the stability of the basement sidewall by substantially increasing the plastic strain and resulting in the initiation of a damage zone, with the addition of water pressure further facilitating this trend. By comparison, the next two construction steps have no evident effect on this area. For the ground near the bottom area of the tunnel wall, although the second step of basement excavation has certain influence on the stability of this area, the addition of water pressure in the tunnel has largely raised the instability of this area, which results in the maximum plastic strain jumping $256.94 \%$ up, significantly more than the increment on the basement sidewall of $71.80 \%$. Moreover, the final step of basement excavation also has an apparent influence on the stability of this bottom area while the further pit excavation has no evident influence on this area. From the field observation mentioned in section 2, the tunnel wall adjacent to the basement collapsed first, resulting in subsequent damage to the excavated basement, meaning that although the variation of plastic strain is higher at the basement sidewall during the first two steps of excavation, it does not lead to the collapse of this area. Instead, the addition of water pressure results in a large increase of the plastic strain at the tunnel wall close to the basement, which significantly affects the stability of the surrounding ground of tunnel and thus is the main factor resulting in the final collapse of the tunnel wall. Given the existing documentation about the locations and extent of failure in the rivulet tunnel, it is legitimate to propose that the simulation results describe a failure model in line with the failure which occurred at this site, i.e., around the tunnel the damage zone appears to be initiated at the ground near the bottom area of the tunnel wall close to the basement and the tunnel wall at this area is the earliest to fail.

\section{Discussions}

The aim of this three-dimensional finite element analysis is to present a back analysis of the excavation-induced tunnel wall movement and damage in the Hobart Myer construction site. The quantification of the effects of excavations and storm-induced stress on the tunnel structure and the surrounding ground is achieved and in this section the influence of meshing size on the obtained displacements and stresses in the numerical model will be firstly discussed, then by combining numerical results and field observation, a reasonable and cogent failure and collapse mechanism of the tunnel will be proposed.

\subsection{Influence of mesh quality on the numerical results}

The accuracy and efficiency of finite element analysis highly depends on the meshing size adopted in the threedimensional model, considering that coarse meshes may result in the decrease of computation precision while fine meshes may lead to the significant increase of computation time. Therefore, a mesh convergence test is necessary in this study to provide a reasonable range of meshing size options that are able to produce efficient and cogent modelling results with the employment of fewer mesh elements.

The variations of maximum displacement and stress values at the monitored plane in figure 7(a) with the introduction of different meshing sizes from coarse to fine are presented in figure 15, from which the variation trend is depicted in a clear, intuitive manner. It should be noted that the tunnel excavation and support installation phases in the test model have been reduced to one analysis step and the first two steps of basement excavation have also been compressed into one analysis step to simplify the computational process. Moreover, the further excavation of three small pits has not been taken into account in the test model as their sizes are too small compared with the whole model, which means their simulations can only be achieved through the employment of relatively fine meshes rather than coarse meshes. 


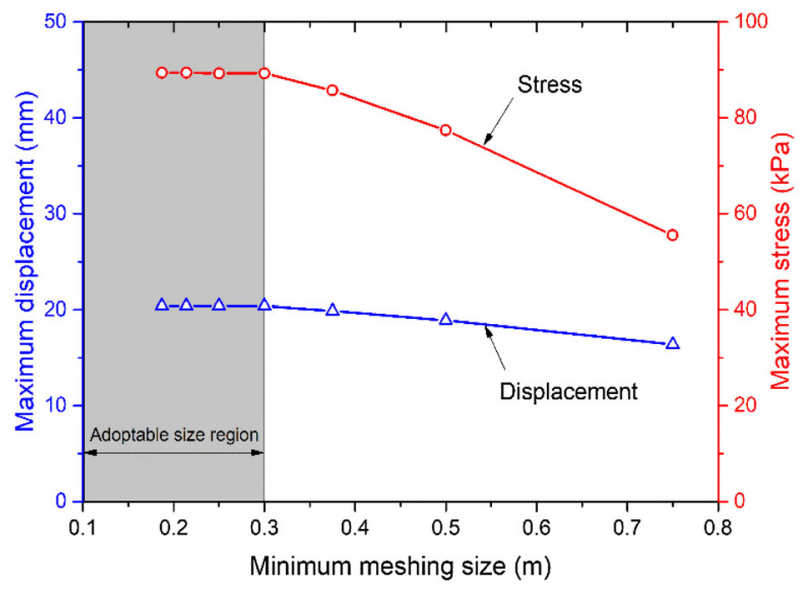

Figure 15. Mesh convergence test for the variations of maximum displacement and stress values at the monitored plane.

The results shown in figure 15 indicate that no obvious changes of displacement and stress values occur after the minimum meshing size decreases to $0.3 \mathrm{~m}$. After employing this meshing size in the simulation of further pit excavation, it is proved that the precision is enough for the successful modelling of the three small pits. Thus, in terms of both computing accuracy and efficiency, this value of minimum meshing size is selected for use in the model.

\subsection{Deductive failure and collapse mechanism of the tunnel}

The failure and collapse mechanism obtained from the three-dimensional finite element analysis indicates that the most conspicuous initiatory damage zones appear at the basement sidewall due to the first two steps of excavation without any support installation, then under the impact of the addition of water pressure in the tunnel, the bottom area of the tunnel wall close to the basement suffers apparent displacement and stress increments and forms new damage zones with an apparent raise of the plastic strains in the surrounding ground. The reason of these obvious variations is that the basement excavation is too close to the existing tunnel and the propagation and coalescence of damage zones between the bottom area of the tunnel wall and the basement sidewall due to the stormwater influence finally result in the instability of the whole region between these two locations and the formation of damage zone. With the further basement and pit excavations, the tunnel structure is more severely affected than the basement sidewall in terms of the variation of the maximum principle plastic strain, which signifies that the previous construction procedures and particularly the added water pressure have inflicted significant damage on the tunnel wall and thus the incapability of the tunnel structure for bearing the further deformation and stress increases is the core reason that results in the final collapse of the whole system.
The observed collapse phenomenon from the construction site reveals that inside buildings close to the basement excavation, the initiation and propagation of cracks on the floor near the tunnel side had been witnessed before the occurrence of the final collapse of the site, which indicates that at that time the bottom area of the tunnel wall close to the basement had deteriorated and the stormwater begun to penetrate into the surrounding ground. With the aggravation of this process due to the continuous excavation, the tunnel wall finally collapsed and the water extensively flooded into the ground, which further damaged the basement sidewall close to the tunnel and resulted in the total collapse of the whole site.

The comparison of modelled results with field observations indicates that the finite element analysis is a cogent explanation of the inner mechanism of failure and collapse for this event, demonstrating a valid mechanism for the initiation, propagation and coalescence of damage zones between the basement and the tunnel wall as well as presenting the variations of displacements and stresses around tunnel that enable the quantifications of the effects of different construction steps on the tunnel structure. This back analysis indicates that when similar situations come up in a construction site, in order to reduce the probability of structural failure and financial loss, it is important that an appropriate support system can be installed during the construction process and that the construction period and technique take into account the influence of storm-induced water pressure on the whole system.

\section{Conclusions}

In an urban area where the construction of new structures in close proximity to existing tunnels is unavoidable, study of the interaction between excavations and these structures is of special importance in helping prevent possible damage or collapse occurring at a site. In this paper, a back analysis of the excavation-induced tunnel wall movement and damage that happened in Hobart at the Myer construction site has been conducted using ANSYS through full three-dimensional finite element calculations coupled with elastoplastic material models. Firstly, the tunnelling process, the installation of support system, the excavation process and the addition of storminduced water pressure are achieved using step-by-step approaches. Then the variations of displacements and stresses through various construction steps in the tunnel support system and the surrounding ground are investigated. Finally, the patterns of the damage zone in the finite element model are analysed with the combination of the variations of maximum principle plastic strains as well as the above obtained displacement and stress modes around the tunnel. Through this study, the following conclusions can be drawn: 
(1) The numerical approach used in this study is efficient for the investigation of the effects of nearby basement excavation on both the support system and the surrounding ground of an existing tunnel taking into account the presence of water pressure in the tunnel.

(2) In this case, throughout all the construction procedures, the initial excavation of basement in the first layer of ground affects the stability of the tunnel support system and the surrounding ground in terms of apparently raising the displacements, stresses and plastic strains at the bottom area of the tunnel wall close to the basement as well as facilities the initiation and centralisation of damage zones at this area. Then the storm-induced water pressure acts on the bottom and sidewalls of the tunnel, resulting in the further formation and propagation of damage zones at the bottom area of the tunnel wall close to the basement and the huge increases of plastic strains at this area. Moreover, the added water pressure has significant impact on the variations of displacement and stress modes in the surrounding ground of tunnel. While the further excavations of basement and three small pits in the second layer of ground only have relatively slight impact on the stress variations in the whole system, the displacement of the tunnel wall close to the basement has been ulteriorly increased and the stability of the tunnel crown far from the basement has lowered. In comparing the severity of impact of each step, it is reasonable to propose that although the collapse of the tunnel wall is a comprehensive result of the nearby basement excavation in the two layers of ground before and after the heavy rainfall, the addition of water pressure in the tunnel is the main factor increasing the instability and resulting in the final collapse of the tunnel wall close to the basement.

(3) As a shallow tunnel evolved from an open drainage channel in soft and weak ground, the formation and later reinforcement processes of the Hobart rivulet tunnel have resulted in a low level of strength and stability in this tunnel. Under the influence of the too-close basement excavation and the storm-induced stress, the stability of the bottom area of the tunnel wall close to the basement has been significantly reduced, resulting in the increased intensity of stress in the damage zone initiated at this area, and further leading to the earliest collapse of the tunnel wall occurring at this location. The collapseinduced structural failure and the stormwater infiltration into the surrounding ground ultimately render the total collapse of the whole system and the resultant damage to the nearby construction site.

\section{Acknowledgements}

The first author thanks the China Scholarship Council (CSC) (No. 201808240013) for a Ph.D. Fellowship support, which enabled him to study in the School of Engineering AMC, University of Tasmania, Australia.

\section{References}

[1] Son M and Cording E J 2005 Estimation of building damage due to excavation-induced ground movements. J. Geotech. Geoenviron. 131: 162-177

[2] Choi J I and Lee S W 2010 Influence of existing tunnel on mechanical behavior of new tunnel. KSCE. J. Civ. Eng. 14: 773-783

[3] Ng C W, Shi J and Hong Y 2013 Three-dimensional centrifuge modelling of basement excavation effects on an existing tunnel in dry sand. Can. Geotech. J. 50: 874-888

[4] Lo K Y and Ramsay J A 1991 The effect of construction on existing subway tunnels-a case study from Toronto. Tunn. Undergr. Sp. Tech. 6: 287-297

[5] Sharma J S, Hefny A M, Zhao J and Chan C W 2001 Effect of large excavation on deformation of adjacent MRT tunnels. Tunn. Undergr. Sp. Tech. 16: 93-98

[6] Dimmock P S and Mair R J 2008 Effect of building stiffness on tunnelling-induced ground movement. Tunn. Undergr. Sp. Tech. 23: 438-450

[7] Tan Y, Li X, Kang Z, Liu J and Zhu Y 2014 Zoned excavation of an oversized pit close to an existing metro line in stiff clay: case study. J. Perform. Constr. Fac. 29: 04014158

[8] Potts D M and Addenbrooke T I 1997 A structure's influence on tunnelling-induced ground movements. In: Proceedings of the Institution of Civil Engineers: Geotechnical Engineering, pp. 109-125

[9] Lee Y J and Bassett R H 2007 Influence zones for 2D pilesoil-tunnelling interaction based on model test and numerical analysis. Tunn. Undergr. Sp. Tech. 22: 325-342

[10] Zheng G and Wei S W 2008 Numerical analyses of influence of overlying pit excavation on existing tunnels. J. Cent. South. Univ. Tech. 15: 69-75

[11] Mirhabibi A and Soroush A 2012 Effects of surface buildings on twin tunnelling-induced ground settlements. Tunn. Undergr. Sp. Tech. 29: 40-51

[12] Augarde C E, Burd H J and Houlsby G T 1995 A threedimensional finite element model of tunnelling. In: Proceedings of NUMOG $V$, Davos, Switzerland, pp. 6-8

[13] Burd H J, Houlsby G T, Augarde C E and Liu G 2000 Modelling tunnelling-induced settlement of masonry buildings. In: Proceedings of the Institution of Civil EngineersGeotechnical Engineering, pp. 17-29

[14] Liu H Y, Small J C and Carter J P 2008 Full 3D modelling for effects of tunnelling on existing support systems in the Sydney region. Tunn. Undergr. Sp. Tech. 23: 399-420

[15] Amorosi A, Boldini D D, De Felice G, Malena M and Sebastianelli M 2014 Tunnelling-induced deformation and damage on historical masonry structures. Geotechnique 64: 118-130

[16] Zidan A F and Ramadan O M O 2015 Three dimensional numerical analysis of the effects of tunnelling near piled structures. KSCE. J. Civ. Eng. 19: 917-928 
[17] Cao C, Shi C, Lei M, Peng L and Bai R 2018 Deformation characteristics and countermeasures of shallow and large-span tunnel under-crossing the existing highway in soft soil: a case study. KSCE. J. Civ. Eng. 22: 3170-3181

[18] Mroueh H and Shahrour I 2003 A full 3-D finite element analysis of tunneling-adjacent structures interaction. Comput. Geotech. 30: 245-253

[19] Franzius J N 2003 Behaviour of buildings due to tunnel induced subsidence. $\mathrm{PhD}$ Thesis. Imperial College of Science, Technology and Medicine, London, UK

[20] Mohamad H, Bennett P J, Soga K, Mair R J and Bowers K 2010 Behaviour of an old masonry tunnel due to tunnelling-induced ground settlement. Geotechnique 60: 927-938
[21] Yoo C 2014 Three dimensional numerical investigation on the effect of bridge construction on existing tunnel. KSCE. J. Civ. Eng. 18: 794-802

[22] Shi J, Ng C W W and Chen Y 2015 Three-dimensional numerical parametric study of the influence of basement excavation on existing tunnel. Comput. Geotech. 63: 146-158

[23] Ng C W W, Fong K Y and Liu H L 2018 The effects of existing horseshoe-shaped tunnel sizes on circular crossing tunnel interactions: Three-dimensional numerical analyses. Tunn. Undergr. Sp. Tech. 77: 68-79

[24] Davies J 1988 Land Systems of Tasmania. Department of Agriculture, Hobart, Tasmania

[25] ANSYS 2016 ANSYS Mechanical APDL Release 18.0

[26] Kelly P 2013 Solid Mechanics Lecture Notes Part II. The University of Auckland 